\title{
THE ALLOCATION OF INVESTMENT IN A DYNAMIC ECONOMY*
}

\author{
Karl Shell and Joseph E. Stiglitz
}

I. Introduction and summary, 592.- II. The one-sector two-capital model, 593.- III. Dynamic analysis, 597.-IV. Market structure, 603.V. Rationality and irrationality, 607.-VI. Concluding comments, 609.

\section{INTROdUCtion aNd SUmmary}

Because contemporary growth theory has focused upon models with a single capital good, ${ }^{1}$ allocation of investment in the dynamic capitalist economy had been uninvestigated until Professor Hahn's recent contribution. ${ }^{2}$ Hahn shows that an economy with several capital goods faces two crucial problems: (1) The growth path may be indeterminate. (2) Not all paths will converge to balanced growth. He concludes that the implications of these problems for the capitalist economy are indeed serious. The purpose of this paper is to examine more closely this indeterminacy and instability.

In our analysis, we employ a model in which consumption is determined by a simple consumption function and the decisions on the allocation of investment among alternative capital goods are made on the basis of short-run profit maximization with short-run perfect foresight about capital gains. In Sections II and III, we show that given initial endowments there exists one and only one assignment of initial prices that is consistent with long-run balanced growth. Furthermore, in the model we treat, whenever momentary equilibrium is not unique, one and only one allocation of investment is consistent with long-run balanced growth. Paths not tending to balanced growth are shown to be intertemporally inefficient. And on such trajectories, the price of one of the capital goods becomes zero in finite time.

* Shell's research was supported in part by a National Science Foundation grant to the Massachusetts Institute of Technology; Stiglitz's research was supported in part by a grant from Gonville and Caius College, Cambridge University. We are indebted to K. J. Arrow, A. B. Atkinson, J. S. Chipman, P. A. Diamond, A. R. Dobell, R. E. Hall, P. A. Samuelson, and R. M. Solow for helpful comments. We alone are responsible for the errors.

1. See, e.g., R. M. Solow, "A Contribution to the Theory of Economic Growth," this Journal, LXX (Feb. 1956), 65-94.

2. F. H. Hahn, "Equilibrium Dynamics with Heterogeneous Capital Goods," this Journal, LXXX (Nov. 1966). Also see F. H. Hahn, "On the Stability of Growth Equilibrium," memorandum, Institute of Economics, University of Oslo, April 19, 1966. 
The instability of the Hahn model is suggestive of the economic forces operating during "speculative booms" like the Tulip Bulb Mania. But such speculative booms seem to be rare exceptions in economic history. What prevents their occurrence? Sections IV and $\mathrm{V}$ are devoted to answering that question.

In Section IV, we investigate in detail the implications of alternative market structures for the pattern of growth. Walrasian futures markets extending indefinitely into the future ensure the stability of the economy. In the case where there are spot markets for used capital but no futures markets, it still remains true that the unique competitive equilibrium path along which expectations are always fulfilled is the path converging to balanced growth. But under our behavioral assumptions about consumption, price expectation formation, and investment allocation, there is no mechanism that will ensure that initial prices chosen today are such that expectations are not disappointed at some later date.

We therefore turn in Section $V$ to an examination of the consequences of a number of alternative market and behavioral assumptions; in particular, it is shown that (1) if there are no markets for selling and renting capital goods, then development of the economy is stable; and (2) if there are imperfections in foresight (if, for instance, individuals have static expectations about prices) the economy is both stable and efficient.

Indeed, in the real world, because individuals do not have confidence in their price expectations, they tend to become skeptical of investments which have low real returns (machines with low marginal products) but high capital gains. Although Walrasian futures markets can ensure dynamic efficiency and stability, it is the "frictions" and "imperfections" in the economy (e.g., imperfect foresight and imperfect used capital goods markets) that probably provide the most important forces for stability and relative efficiency.

\section{The One-Sector Two-Capital Model}

Both the instability of long-run equilibrium and the lack of uniqueness of momentary equilibrium which Hahn observed in his multi-sector Cobb-Douglas economy can be studied in a one-sector economy with two capital goods. ${ }^{3}$ This will allow us to give the complete dynamic analysis, which was lacking in the more compli-

3. Or equivalently, a three-sector model in which the capital intensities in all sectors are identical. 
cated Hahn formulation. To make our analysis as close as possible to that of Hahn, we shall use the Cobb-Douglas production function to illustrate the more general problem. Then the production function can be written as

$$
\begin{aligned}
& Q=F\left(K_{1}, K_{2}, L\right)=K_{1} a_{1} K_{2} a_{2} L^{1-a_{1}-a_{2}, a_{1}}>0, a_{2}>0, \\
& 1-a_{1}-a_{2}>0,
\end{aligned}
$$

where $K_{i}(i=1,2)$ is the quantity of the $i$ th capital good, $L$ is labor, and $Q$ is output. Letting $k_{1}=\left(K_{1} / L\right)$ and $k_{2}=\left(K_{2} / L\right)$ yields

$$
Q=L f\left(k_{1}, k_{2}\right)=L k_{1} a_{1} k_{2} a_{2} \text {. }
$$

Since the consumption good and both investment goods are assumed to be produced by the same production function

$$
Q=Z_{1}+Z_{2}+C=K_{1}^{\prime}+\mu K_{1}+K_{2}^{\prime}+\mu K_{2}+C,
$$

where $C \geqslant 0$ is consumption, $Z_{i}=K_{i}^{\prime}+\mu K_{i} \geqslant 0$ is gross investment in the $i$ th capital good $(i=1,2)$, and $\mu>0$ is the constant rate of exponential depreciation (assumed to be equal for the two capital goods). ${ }^{4}$ Once installed, the machines are bolted-down in the sense that they can no longer be transformed one into the other or into consumption goods.

Following Hahn, we assume that all profits are invested and all wages consumed.

$$
C=F_{L} L=\left(f-k_{1} f_{1}-k_{2} f_{2}\right) L=\left(1-a_{1}-a_{2}\right) Q,
$$

where $F_{L} \equiv \partial F / \partial L$ and $f_{i} \equiv \partial f / \partial k_{i}$. Since the production supply prices of all three commodities are identical (since they are produced by the same production function), only the commodities with the highest market prices are produced. By assumption, wage and rental rates are equal to the marginal products of labor and capital, respectively, and since these are always positive, both consumption and investment are also always positive. Hence, taking the consumption good as numéraire we have

(2.4) $\max \left[p_{1}, p_{2}\right]=p_{c} \equiv 1$,

where $p_{c}, p_{1}$, and $p_{2}$ are the prices of the consumption good, the first investment good, and the second investment good, respectively. Of course, the equilibrium market price of output is always equal to the price of consumption, or $\max \left(p_{1}, p_{2}, 1\right)=1$. Under our savings hypothesis, the equations of capital accumulation are

$$
\begin{aligned}
& k_{1}{ }^{\prime}=z_{1}-\lambda k_{1}=\sigma\left(k_{1} f_{1}+k_{2} f_{2}\right)-\lambda k_{1}, \\
& k_{2}{ }^{\prime}=z_{2}-\lambda k_{2}=(1-\sigma)\left(k_{1} f_{1}+k_{2} f_{2}\right)-\lambda k_{2},
\end{aligned}
$$

4. Primes are used to denote time differentiation. For example, $K_{i}^{\prime} \equiv d K_{i} / d t$. 
where $z_{i} \equiv Z_{i} / L(i=1,2)$ and $\sigma$ depends upon $\left(p_{2} / p_{1}\right)$ and is given by

$$
\sigma \begin{cases}=1 & \text { if } p_{2}<p_{1}, \\ \epsilon[0,1] & \text { if } p_{2}=p_{1}, \\ =0 & \text { if } p_{2}>p_{1},\end{cases}
$$

and $\lambda$ is the sum of the rates of depreciation and population growth, both of which are assumed to be constant. That is, only the investment good with the higher price is produced..$^{5}$ Since wages are equal to consumption, rentals must equal gross investment. However, when $p_{1}=p_{2}$, momentary equilibrium is not unique. A momentary equilibrium is an allocation of output among the consumption good and the two investment goods that satisfies our static behavioral relations (2.2) to (2.5), for currently given capital stocks, labor force, and prices. Nothing in this system determines the value of $\sigma$ between 0 and 1 when $p_{1}=p_{2}$. In Figure I, we have drawn the

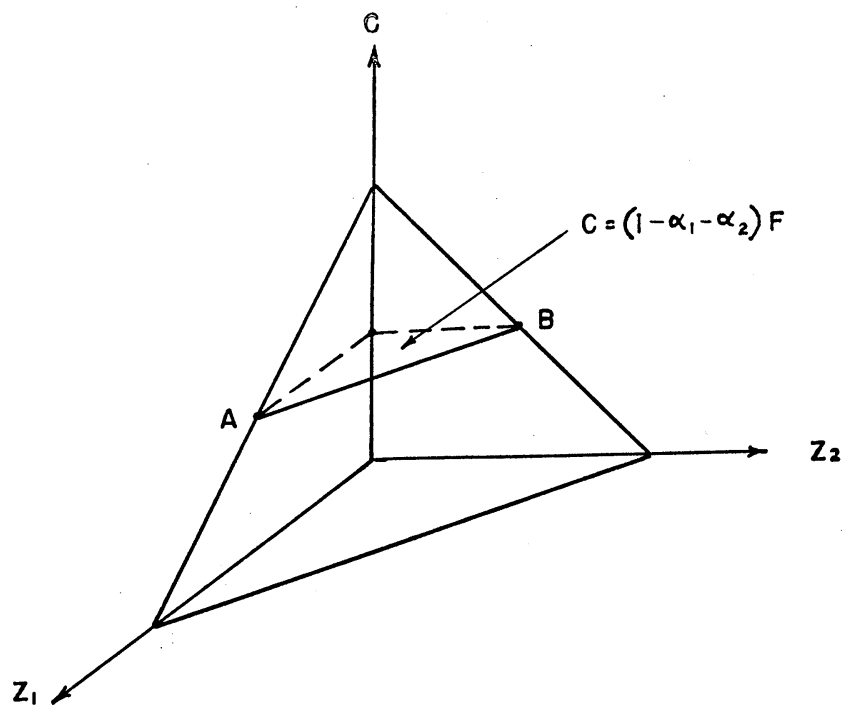

Fiaure I

production possibility frontier. We have then drawn, for the CobbDouglas case, the consumption line, which is the intersection of the production possibility frontier with a plane parallel to the $\left(Z_{1}, Z_{2}\right)$ plane and intersecting the $C$ axis at a value equal to $\left(1-a_{1}-a_{2}\right) F$.

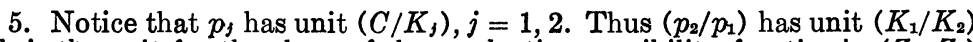
which is the unit for the slope of the production possibility frontier in $\left(Z_{1}, Z_{2}\right)$ space. By the one-sector assumption, the absolute value of the slope of the $P P F$ is unity.

" $\sigma \in[0,1]$ " should be read as " $\sigma$ belongs to the closed unit interval," i.e., $\sigma$ is such that $0 \leq \sigma \leq 1$. 
If $p_{1}>p_{2}$, it is clear that the economy operates at point $A$, while if $p_{1}<p_{2}$, it operates at point $B$. But if $p_{1}=p_{2}$, any point along the line $A B$ is technologically and socially feasible. ${ }^{6}$

Thus far, we have discussed the markets equating demand and supply of consumption goods and demand and supply of investment goods. But we have yet to discuss the markets for already existing capital goods. We consider an individual at the beginning of the period with one unit of capital good one. He can hold this capital good and at the end of the period, the expected change in the value of his net worth will be $(1-\mu \Delta t) \eta_{1}{ }^{t+\Delta t}+r_{1} \Delta t-p_{1}{ }^{t}$, where $\eta_{1}{ }^{t+\Delta t}$ is the expected price of his unit of $K_{1}$ at the end of the period; $r_{1}$ is the average gross rentals (in units of output per unit of time) he gets from the ownership of a unit of $K_{1}$ and $\mu$ is the rate of depreciation per unit of time.

Alternatively, he could have sold his unit of $K_{1}$, received $p_{1}{ }^{t}$ for it, purchased $p_{1}{ }^{t} / p_{2}{ }^{t}$ units of $K_{2}$, and at the end of the period he would expect his net worth to have increased by $\left(p_{1}^{t} / p_{2}{ }^{t}\right)\left[(1-\mu \Delta t)_{\eta_{2}}{ }^{t+\Delta t}+r_{2} \Delta t-p_{2}^{t}\right]$. In equilibrium, the expected returns are the same, i.e.,

$\frac{(1-\mu \Delta t) \eta_{1}{ }^{t+\Delta t}+r_{1} \Delta t-p_{1}{ }^{t}}{p_{1}{ }^{t}}=\frac{(1-\mu \Delta t) \eta_{2}{ }^{t+\Delta t}+r_{2} \Delta t-p_{2}{ }^{t}}{p_{2}{ }^{t}}$.

If individuals have short-run perfect foresight, so that expectations about price changes are realized, ${ }^{7}$ then

$$
\eta_{1}{ }^{t+\Delta t}=p_{1}{ }^{t+\Delta t} \text { and } \eta_{2}{ }^{t+\Delta t}=p_{2}{ }^{t+\Delta t} \text {. }
$$

Dividing by $\Delta t$, and taking the limit as $\Delta t \rightarrow 0$ yields ${ }^{8}$

6. Had there been curvature to the production possibility frontier, specifying the market price ratios would have uniquely specified the output bundle. The question would then be: What restrictions do we have to impose upon the production functions of a many-capital-goods, many-sector model to ensure that for any two capital goods $i$ and $j,\left(\partial^{2} Z_{i} / \partial Z_{j}^{2}\right)$ be nonzero along the production possibility frontier? This is the problem of uniqueness of momentary equilibrium that Hahn treats in his recent paper (op. cit., pp. 638-41).

7. "Short-run perfect foresight" may also be called "myopic foresight" since at any point the individual only knows the price at the next "moment." This is closely related to the notion of "instantaneous adjustment" which arises in the theory of adaptive expectations. The adaptive expectations hypothesis is that $\xi^{\prime}=b[\theta-\xi]$, where $\xi$ is the expected rate of price change, $\theta$ is the actual rate of price change, and $b$ is the coefficient of adjustment. $b=0$ is the case of static expectations. As $b \rightarrow \infty$ the hypothesis becomes that of instantaneous adjustment and can be interpreted as follows: Individuals expect the right-hand time derivatives of price to be equal to their (actual) left-hand derivatives. "Long-run perfect foresight," on the other hand, means that individuals have expectations today about all future prices and that these expectations are fulfilled.

8. To see that the dimensions of the terms are consistent, write down the units of each as follows:

$$
\frac{C / K_{1} t}{C / K_{1}}+\frac{C / K_{1} t}{C / K_{1}}-1 / t=\frac{C / K_{2} t}{C / K_{2}}+\frac{C / K_{2} t}{C / K_{2}}-1 / t=1 / t \text {. }
$$




$$
p_{1}^{\prime} / p_{1}+r_{1} / p_{1}-\mu=p_{2}^{\prime} / p_{2}+r_{2} / p_{2}-\mu \equiv \rho
$$

where $\rho$ is the rate of return. In a competitive economy $r_{1}$ and $r_{2}$ are equated to the value marginal products of $K_{1}$ and $K_{2}$, respectively. Since consumption and investment are both positive, in a one-sector model the price of output will be equal to the price of consumption $(=1)$. Therefore, for a competitive economy $r_{1}=f_{1}$ and $r_{2}=f_{2}$.

Therefore, we know that under short-run perfect foresight with short-run profit maximization

$$
p_{1}^{\prime} / p_{1}+f_{1} / p_{1}-p_{2}{ }^{\prime} / p_{2}-f_{2} / p_{2}=0 \text {. }
$$

Note that we have assumed throughout this discussion that $p_{1}$ and $p_{2}$ are positive. In Sections IV and V, we will focus on what happens when one of the two prices becomes equal to zero.

Balanced Growth. Since the labor force growth rate is constant, balanced growth implies that $k_{1}$ and $k_{2}$ are constant. For $k_{1}$ and $k_{2}$ to remain constant, both capital goods must be produced, and hence both must have a price equal to the price of consumption goods (=1).9 Thus, in the balanced state both $p_{1}{ }^{\prime} / p_{1}$ and $p_{2}{ }^{\prime} / p_{2}$ must be zero. Hence from (2.6), $f_{1}=f_{2}$. From (2.5), setting $k_{1}{ }^{\prime}=0=k_{2}{ }^{\prime}$ gives $\lambda\left(k_{1}+k_{2}\right)=f_{1} k_{1}+f_{2} k_{2}=f_{1}\left(k_{1}+k_{2}\right)$, or $\lambda=f_{1}=f_{2}$.

We now show that for the Cobb-Douglas case there exists a unique balanced growth path. Notice that $f_{1}=f_{2}$ if and only if $k_{1}=a_{1} k_{2} / a_{2}$. For the Cobb-Douglas case, when $f_{1}=f_{2}$

$$
f_{1}=\left(a_{1}\right)^{1-a_{2}} a_{2} a_{2} k_{1} a_{1}+a_{2}-1 .
$$

Differentiating the above with respect to $k_{1}$ shows that $f_{1}$ is decreasing in $k_{1}$ along the line $f_{1}=f_{2}$. Therefore $f_{1}=f_{2}=\lambda$ for at most one value of the vector $\left(k_{1}, k_{2}\right)$. Since along $f_{1}=f_{2}$

$$
\lim _{k_{1} \rightarrow 0} f_{1}=\infty \text { and } \lim _{k_{1} \rightarrow \infty} f_{1}=0,
$$

the solution $\left(k_{1}{ }^{*}, k_{2}{ }^{*}\right)$ to the system $f_{1}=a_{1} f / k_{1}=f_{2}=a_{2} f / k_{2}=\lambda$ is uniquely determined. ${ }^{1}$

\section{Dynamic Analysis}

There are three different regimes in which the economy may find itself:

Regime I. $p_{2}<p_{1}=1$, only capital good 1 is produced $(\sigma=1)$.

9. If the Inada conditions are not satisfied, so $f\left(0, k_{2}\right)>0$, for instance, there may exist a balanced growth path with $k_{1}$ not produced. See below, p. 603.

1. For the more general case where the two capital goods are complements $\left(f_{12}>0\right)$, the analysis is virtually unaltered. 
Regime II. $1=p_{2}>p_{1}$, only capital good 2 is produced $(\sigma=0)$. Regime III. $p_{1}=p_{2}=1, \sigma$ is indeterminate.

The differential equations (2.5) and (2.6) reduce to (using 2.4) : ${ }^{2}$

\begin{tabular}{|c|c|c|}
\hline Regime I & Regime II & Regime III \\
\hline $\begin{array}{l}\text { (3.1.I) } k_{1}^{\prime}=\pi-\lambda k_{1} \\
(32 . I) k_{2}^{\prime}=-\lambda k_{2} \\
\text { (3.3.I) } p_{1}^{\prime}=0 \\
\text { (3.4.I) } p_{2}^{\prime}=p_{2} f_{1}-f_{2}\end{array}$ & $\begin{array}{l}\text { (3.1.II) } k_{1}^{\prime}=-\lambda k_{1} \\
\text { (3.2.II) } k_{2}^{\prime}=\pi-\lambda k_{2} \\
\text { (3.3.II) } p_{1}^{\prime}=p_{1} f_{2}-f_{1} \\
\text { (3.4.II) } p_{2}^{\prime}=0\end{array}$ & $\begin{array}{l}\text { (3.1.III) } k_{1}^{\prime}=\sigma \pi-\lambda k_{1} \\
\text { (3.2.III) } k_{2}^{\prime}=(1-\sigma) \pi-\lambda k_{2} \\
\text { (3.3.III) } p_{1}^{\prime}=\rho+\mu-f_{1} \\
\text { (3.4.III) } p_{2}^{\prime}=\rho+\mu-f_{2}\end{array}$ \\
\hline
\end{tabular}

where profits per capita $\pi=\left(a_{1}+a_{2}\right) q$ with $q$ denoting output per capita.

Although this is a system of four "differential equations" in $k_{1}$, $k_{2}, p_{1}$, and $p_{2}$, our simple assumptions about production and demand for consumption allow us to make a complete dynamic analysis of the system in $\left(k_{1}, k_{2}\right)$ "phase" space. In Figure II we have drawn the ray $O A$ along which $k_{1}=k_{2} a_{1} / a_{2}$ (i.e., along which $f_{1}=f_{2}$ ). Above $O A, f_{2}>f_{1}$; below $O A, f_{1}>f_{2}$.

In Regime I, $k_{1}{ }^{\prime}=0$ along the curve denoted in Figure II by $O B$ which is the locus of points such that

$$
k_{1}=\left[\frac{\left(a_{1}+a_{2}\right) k_{2} a_{2}}{\lambda}\right]^{\frac{1}{1-a_{1}}} .
$$

Differentiating yields

$$
\left(\frac{d k_{1}}{d k_{2}}\right)_{\substack{k_{1}^{\prime}=0 \\ \sigma=1}}>0 \text { and }\left(\frac{d^{2} k_{1}}{d k_{2}^{2}}\right)_{\substack{k_{1}^{\prime}=0 \\ \sigma=1}}<0 .
$$

Similarly for Regime II we can describe the locus of points such that $k_{2}{ }^{\prime}=0$, and this curve is denoted in Figure II by the curve $O C$.

Thus, Figure II is divided into six basic regions: $A_{1}$ which lies to the right of the $k_{1}$ (vertical) axis and above $O A, O B$, and $O C$;

2. It is important to observe that because $\sigma$ is an upper semicontinuous correspondence, (2.5) and (2.6) do not define a dynamical system of the sort treated in the standard mathematical treatises. The solutions, $k_{1}(t), k_{2}(t), p_{1}(t)$ and $p_{2}(t)$ can be shown, however, to be continuous although not in general differentiable.

While the economy is in Regime $I, \sigma=1$, and the solution to (2.5) is continuous. Hence, $f_{1}$ and $f_{2}$ are continuous and bounded, so $p_{1} / p_{2}$ is continuous (by 2.6). Thus, by $(2.4) ; p_{1}$ must remain at unity; so $p_{1}^{\prime}=0$. Similarly in Regime II. In Regime III the value of $\sigma \epsilon[0,1]$ is undetermined. (To avoid pathologies we assume that there are at most a finite number of discontinuities in $\sigma$ in any finite interval of time.) If Regime III is to be maintained, $p_{1}=p_{2}=1$, so $p_{1}^{\prime}=p_{2}^{\prime}=0$, and $\sigma$ must be chosen so that $f_{1}=\rho+\mu=f_{2}$. Thus, $k_{1} / k_{2}$ must remain constant, and since $k_{1}+k_{2}$ is continuous, $k_{1}$ and $k_{2}$ must be continuous. 


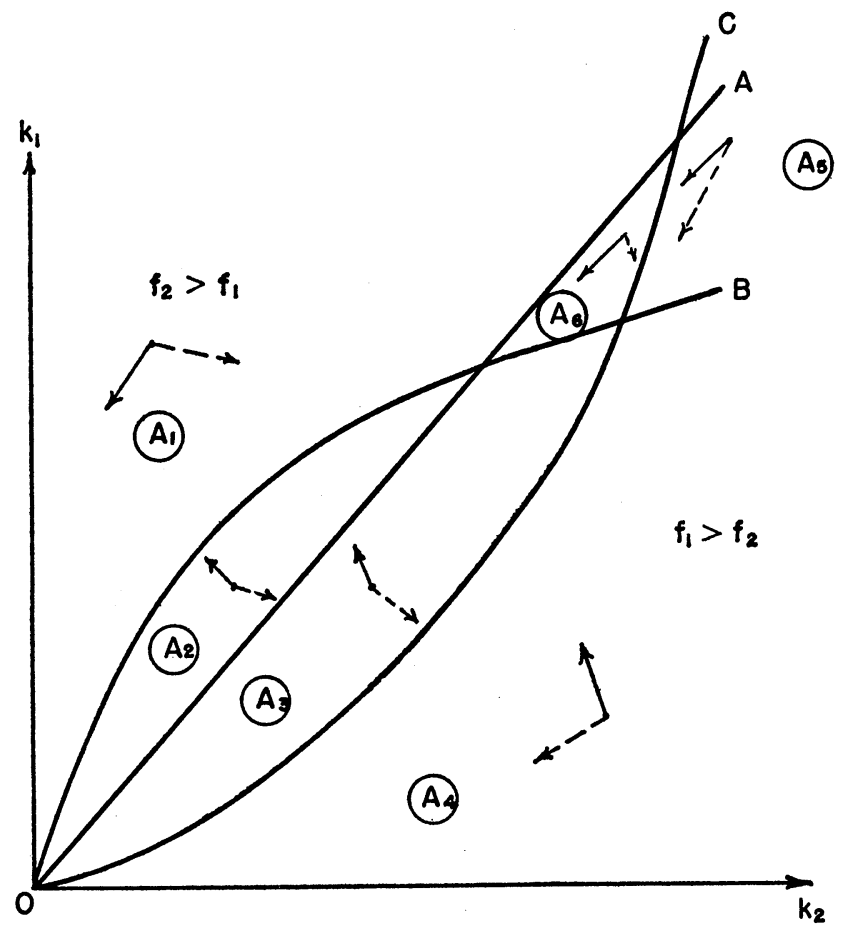

FIgure II

$A_{2}$ which lies above $O A$ and below $O B ; A_{3}$ which lies above $O C$ and below $O A$ and $O B ; A_{4}$ which lies above the $k_{2}$ (horizontal) axis and below $O C$ and $O B ; A_{5}$ which lies above $O B$ and below $O C ; A_{6}$ which lies below $O A$ and above $O B$ and $O C$. The solid arrows indicate the direction of development in the respective regions when $\sigma=1$ (Regime I). The dashed arrows indicate the direction of development when $\sigma=0$ (Regime II).

So far, we have ignored the behavior of prices. We recall that in Regime I, $p_{2}^{\prime} / p_{2}=f_{1}-f_{2} / p_{2}$. If the economy is in Regime I and above $O A$ (i.e., $f_{2}>f_{1}$ ), we know that $f_{1}<f_{2} / p_{2}$ since $p_{1}>p_{2}$. Thus, in this case $p_{2}$ falls and as long as the economy is above $O A$ it cannot switch to Regime II. It continues to specialize investment in the capital good with the lower marginal product - a clear instance of the Keynesian ${ }^{3}$ disparity between social and private returns due to capital gains. Similarly, if the economy is in Regime II and below $O A$, as long as it is below $O A$ it cannot switch to Regime I.

We are now ready to put all this information to use for a full

3. See J. M. Keynes, The General Theory of Employment, Interest, and Money (New York: Harcourt, Brace, 1936), esp. Chap. 12. 
dynamic analysis. Consider, for example, an economy which begins initially in $A_{2}$. If the economy begins with $p_{1}>p_{2}$ (i.e., in Regime I), it must remain in Regime I, so that the economy moves towards the curve $O B$, crosses it, and then moves towards the origin.

If initially $p_{2}>p_{1}$ and initially the economy is in $A_{2}$, it moves towards $O A$, but since $p_{1}^{\prime} / p_{1}=f_{2}-f_{1} / p_{1}$ and $f_{1}<f_{2}$, if $p_{1}$ is sufficiently large $\left(>f_{1} / f_{2}\right), p_{1}$ is rising. It is possible then that, before the economy gets to $O A, p_{1}$ becomes equal to $p_{2}(=1){ }^{4}$ But since $f_{1}<f_{2}, p_{2}$ must begin to fall, ${ }^{5}$ and we switch to Regime I. From then on the story follows as before. Alternatively, the economy can cross the ray $O A$ with $p_{2}$ greater than $p_{1}$. The story for the economy in Regime II in $A_{3}$ is analogous to that of the economy in Regime I in $A_{2}$. The economy moves to $O C$, crosses it and proceeds to the origin.

One important case remains: The economy begins in $A_{2}$ with $p_{2}>p_{1}$, but $p_{1}=p_{2}$ at exactly the moment that $f_{1}=f_{2}$. The economy is then in Regime III in which momentary equilibrium is not unique. ${ }^{6}$ There is a unique allocation $\sigma^{*}$ which will enable the economy to move along the ray $O A$ to the steady-state solution; we require $k_{1}^{\prime} / k_{2}^{\prime}$ to equal the slope of $O A$

$$
\frac{a_{1}}{a_{2}}=\frac{\sigma^{*} \pi-\lambda k_{1}}{\left(1-\sigma^{*}\right) \pi-\lambda k_{2}}
$$

4. Observe that in this case, at the point where $p_{1}=p_{2}$, the system lacks uniqueness of monetary equilibrium. But this nonuniqueness lasts only for a moment. The amount of capital accumulation which occurs during that moment is infinitesimal, regardless of the value which $\sigma$ takes on in that moment. The next moment, $p_{2}>p_{1}$, and the economy's path is unaffected by what happens in the moment of nonuniqueness of equilibrium. Hence, although the economy lacks uniqueness of momentary equilibrium, it is not causally indeterminate.

5. Since $p^{\prime}{ }_{1} / p_{1}-p_{2}^{\prime} / p_{2}=f_{2} / p_{2}-f_{1} / p_{1}>0, p_{1}$ must fall relative to $p_{2}$, but $\max \left(p_{1}, p_{2}\right)=1$, so $p_{2}$ remains at 1 , and $p_{2}$ falls below 1 .

6. It can be shown that for any given initial endowment there exists one and only one initial price assignment which will get the economy to the $O A$ ray at exactly the same moment that $p_{1}=p_{2}=1$. Observe that if the economy begins above $O A$ and remains in Regime II, it must, in finite time, cross $O A$, since

$$
\frac{d \log \left(k_{2} / k_{1}\right)}{d t}=\pi / k_{2}>0 \text {. }
$$

The right-hand side, in the region above $O A$, is clearly bounded away from zero, and hence in finite time, for all initial values of $k_{1} / k_{2}$ greater than $a_{1} / a_{2}$. the economy eventually reaches $O A$. The behavior of the real system (i.e., $k_{1}, k_{2}$ ) is independent of the particular prices chosen, provided that we remain in Regime II. Hence, the values of $k_{1}$ and $k_{2}$ along the path which goes from the initial value of $\left(k_{1}, k_{2}\right)$ to a point on $O A$ are determined at every point of time, and continuous in time and consequently, $f_{1}$ and $f_{2}$ are determined as continuous functions of time alone. Since the Cobb-Douglas production function is analytic, the price differential equation satisfies the Lipschitz condition and hence the price differential equation, with the terminal condition $p_{1}\left(t^{*}\right)=1$ where $t^{*}$ is the time at which $f_{1}=f_{2}$, has a unique backward solution. 
or

$$
0<\sigma^{*}=\frac{a_{1}}{a_{1}+a_{2}}<1 .
$$

If $\sigma$ deviates from $\sigma^{*}$ for more than an infinitesimal length of time, clearly $f_{1}$ will no longer equal $f_{2}$. If, for instance, $\sigma<\sigma^{*}, k_{2}$ becomes slightly greater than $a_{2} k_{1} / a_{1}$, i.e., $f_{1}$ becomes greater than $f_{2}$. Our price differential equation, for Regime III, is $p_{2}{ }^{\prime}-p_{1}{ }^{\prime}=$ $f_{1}-f_{2}>0$. Hence $p_{1}$ decreases relative to $p_{2}(=1)$, and the economy moves into Regime II. From then on, the story is familiar.

But in the model as presented thus far there is no mechanism with only short-run perfect foresight by which $\sigma$ can be maintained at $\sigma^{*}$.

The dynamic behavior for the economy with initial endowments in other regions can be analyzed in a similar manner. ${ }^{7}$ For each initial assignment of the endowment vector $\left(k_{1}, k_{2}\right)$, there is one and only one assignment of initial prices $\left(p_{1}, p_{2}\right)$ that allows the economy to proceed to long-run balanced growth. We have shown that, if we assign $\sigma=\sigma^{*}$ in Regime III, the unique balanced growth equilibrium is a saddlepoint in the $\left(k_{1}, k_{2}, p_{1}, p_{2}\right)$ phase-space. ${ }^{8}$ So far, there is no mechanism endogenous to the model which ensures that initial prices will be chosen so as to allow for long-run balanced growth. Paths not tending toward balanced growth tend to the origin, and even along paths which allow for long-run balanced growth there is no mechanism to ensure that $\sigma=\sigma^{*}$ in Regime III.

Moreover, along paths not tending to balanced growth, the price of one of the two capital goods goes to zero in finite time. ${ }^{9}$ To see this, consider once again the economy above $O A\left(f_{2}>f_{1}\right)$ but in Regime I. Defining $\beta=f_{1} / f_{2}$ and using (3.4.I) yields

$$
p_{2}^{\prime}=\left(p_{2} \beta-1\right) f_{2}<0 .
$$

7. If the economy begins in $A_{1}$ in Regime II, it either moves into $A_{2}$, from which point the story is familiar, or $p_{2}=p_{1}$ before the economy gets to $O B$ in which case it switches to Regime I. But in Regime I and in $A_{1}$, the economy cannot switch to Regime II and must proceed toward the origin $\mathbf{0}$. The behavior in $A_{3}$ and $A_{4}$ is symmetrical to that in $A_{1}$ and $A_{2}$. Observe from Figure II that an economy in $A_{5}$ or $A_{6}$ ultimately must proceed to $A_{1}, A_{2}, A_{3}$ or $A_{4}$.

8. It is important to remember that $\sigma$ is not a single valued function of $p_{1}$ and $p_{2}$. Therefore, the usual associated-linear-system analysis cannot be performed because $\sigma$ is not single valued at equilibrium. However, since $\sigma$ is an upper-semi-continuous correspondence in $\left(p_{1} / p_{2}\right)$ and is single valued when $p_{1} \neq p_{2}$, our analysis is equivalent to that of "splicing together" along the $p_{1}=p_{2}$ hyperplane two separate Lipschitzian differential equation systems. Since $\sigma$ is not single valued, we might say that the system (3.1) to (3.4) possesses a generalized saddlepoint equilibrium.

9. Assuming, of course, that initial prices are positive. 
Observe that in this case $\beta$ is declining through time. This is because $\beta$ is a constant along every ray through the origin (where $\beta$ decreases as the slope of the ray increases), and the path of development cuts every ray from the right. Also in this case, $f_{2}$ is increasing through time since

$$
\frac{d \log f_{2}}{d t}=\left(1-a_{1}-a_{2}\right) \lambda+\frac{a_{1} \pi}{k_{1}}>0 .
$$

Therefore, from (3.5), $p_{2}$ is falling at a rate faster than a constant absolute rate. ${ }^{1}$ Thus, for all paths not leading to long-run balanced growth, the price of the capital good with the higher marginal product goes to zero in finite time.

It should be remarked that all such programs of accumulation not converging to balanced growth ultimately reveal themselves to be permanently inefficient. Since on the path tending to balanced growth, investment is always specialized to the capital with the higher marginal product, output (and thus consumption!) is highest at every instant. Thus, in the sense of Phelps-Koopmans, the path leading to balanced growth dominates all other paths satisfying the system (3.1) to (3.4). From Figure II, it can be seen that paths not converging to balanced growth ultimately have both $k_{1}$ and $k_{2}$ decreasing. There exists a finite time after which the balanced growth capital stocks are both higher than on a nonbalanced growth comparison path. Thus, in the sense of Dorfman-Samuelson-SolowRadner finite time criterion, the path tending to balanced growth dominates all other paths satisfying (3.1) to (3.4). ${ }^{2}$ Not only does a short-run perfect foresight price system generate dynamic instability in our model competitive economy, but it may also lead to intertemporal inefficiency in the allocation of investment. ${ }^{3}$

$$
\text { 1. } p^{\prime} \leqslant\left(\frac{p_{2}(0) f_{1}\left(k_{1}(0), k_{2}(0)\right)}{f_{2}\left(k_{1}(0), k_{2}(0)\right)}-1\right) f_{2}\left(k_{1}(0), k_{2}(0)\right)<0
$$

for all $k_{1}(0)$ above $O A$ and $p_{2}(0)<1$. Strictly speaking, equation $(2.6)$ is defined only for nonnegative prices. In Sections IV and V, we focus on what happens when one of the prices goes to zero.

2. The system (3.1) to (3.4) is similar in structure to the necessary Euler-Lagrange equations derived from certain Ramsey-type planning models. In fact if the Ramsey model is such that the Euler-Lagrange equations are autonomous, equilibrium is of the saddlepoint (or generalized saddlepoint) type. See, e.g., P. A. Samuelson and R. M. Solow, "A Complete Capital Model Involving Heterogeneous Capital Goods," this Journal, LXX (Nov. 1956), 537-62. In the planning models it is also necessary that certain transversality conditions be satisfied. In Sections IV and V of this paper, we try to answer the question: Are there or are there not mechanisms in the capitalist economy ensuring stability and efficiency of development?

3. This statement will have to be qualified in Sections IV and V of this paper, in which we investigate the implications of various assumptions about markets and behavior. We do know, however, that for arbitrarily assigned initial prices, an economy following the system (3.1) to (3.4) may not be efficient. 
Many of the special assumptions of the model presented above may be altered without changing the basic results: (1) Fixed coefficients technology. In this case, the economy will converge to balanced growth only if initial prices are chosen so that

$$
\frac{p_{2}(0)}{p_{1}(0)}=\frac{a_{2} k_{1}(0)}{a_{1} k_{2}(0)}
$$

where $q=\min \left[k_{1} / a_{1}, k_{2} / a_{2}\right]$. (2) The production function $q=$ $\left(k_{1}+k_{2} a\right)^{a}$. This special case illustrates some of the problems that occur when capital goods are substitutes $\left(f_{12}<0\right)$. Also, this production function is a particularly interesting example because inefficient investment programs are so easy to recognize. If $a>1$, a program with investment in $K_{1}$ is inefficient; if $a<1$, a program with investment in $K_{2}$ is inefficient; if $a=1$, then the allocation of investment is a matter of indifference. Using the fact that everywhere $f_{2}=a f_{1}$, yields that, for the case $a>1$, there exists a unique balanced path $p_{1}=1 / a, p_{2}=1, k_{1}=0, k_{2}=\left[a a^{a} / \lambda\right]^{\frac{1}{1-a}}$. For all initial assignments of the price vector but $(1 / a, 1)$, one of the prices goes to zero in finite time and tends ultimately to minus infinity. But on such "errant" paths the real variables do not tend to the origin as is the case when capital goods are complements. If initially $p_{1}<1 / a$, the system tends to $k_{1}=0, k_{2}=\left[a a^{a} / \lambda\right]^{\frac{1}{1-a}}$, whereas if initially $p_{1}>1 / a$ the system tends to $k_{1}=[a / \lambda]^{\overline{1-a}}, k_{2}=0$. Thus, for initial $p_{1} \leq 1 / a$, development of the real system is efficient, for initial $p_{1}>1 / a$, development is inefficient. (3) Different production functions in the different sectors. For cases like that treated by Hahn where there exists a unique balanced growth equilibrium, we conjecture, although have not proved, that the balanced growth equilibrium is of the (generalized) saddlepoint type. (4) Savings a constant fraction of income including capital gains. The dynamic analysis is basically unaltered but one further point arises. Capital gains can get so large that all of output is devoted to consumption, or capital losses can get so large that all of output is devoted to saving.

\section{Market Structures}

There are (at least) two different assumptions about market structure which are consistent with the model already presented: futures markets today for all periods into the future, and perfect 
spot markets without futures markets. Not surprisingly, it turns out that these different assumptions have very different implications for the behavior of the economy. 4

A. Futures markets for all periods into the future. As in the usual Walrasian analysis, we require all markets to be in equilibrium before any actual transactions take place. ${ }^{5}$ Assume that the auctioneer called off a set of prices corresponding to an "errant path," i.e., a path not converging to balanced growth. Recall that on such paths the price of one of the capital goods goes to zero in finite time. If capital goods are freely disposable, prices cannot become negative; when the price of a capital good is zero, capital gains must be nonnegative; but since rentals are positive, the rate of return is infinite. The other capital good has, of course, a finite rate of return. Hence, everyone demands the capital good whose price has become zero, and the market does not clear. The only trajectory along which markets will clear at all periods of time is the unique path converging to balanced growth. Thus, if Walrasian futures markets extending infinitely far into the future all clear, the economy must converge to balanced growth. (It should be clear that this is not a tautological statement.) Notice, however, that if futures markets extend only a finite time into the future (no matter how far), the economy may follow an errant trajectory since all markets within that finite "horizon" may clear. ${ }^{6}$

In the real world, there are, as we have suggested, futures

4. As we have already noted, the dynamical system of our model is similar to that of a planned economy. But the questions on which we focus in this and the following section have meaning only for a market economy. For although the balanced growth equilibrium is a saddlepoint, in principle the planner can at any time correct any deviations from the optimal trajectory. As Samuelson and Solow pointed out, "This re-aiming is, so to speak, what an optimizing society is constantly doing." Op. cit., p. 548.

5. The few futures markets which exist (usually in agricultural commodities) bear only a faint resemblance to these Walrasian markets. The fact that in the real world individuals cannot make transactions today which are binding on their heirs makes the assumption of an atemporal (once-and-for-all) Walrasian market particularly implausible.

It should be stressed that there is no need to consider price expectations in the atemporal Walrasian market. The auctioneer calls out trial prices for all dates; no contracts are binding until the auctioneer finds the full set of market clearing prices.

6. But it will not follow the path forever. In finite time, one of the futures markets will not clear and the economy will set off on another trajectory.

If, however, capital goods are not disposable (at any cost) then, prices can clearly be negative. Then the argument that Walrasian futures markets ensure stability, holds with important modifications. When $p_{2}=0$, utilitymaximizing individuals will demand an infinite amount of $K_{2}$ (since it is costless but yields positive rentals). Thus markets will not clear. A similar argument holds for the next subsection. 
markets for only a few commodities, and those that do exist, extend only for a few periods into the future. Moreover, Hahn probably did not have this market structure in mind when he posed the problem of stability of the economy; Walrasian (once-and-for-all) markets make the problem of allocation an atemporal one. We turn, therefore, to the market economy with spot markets but without futures markets.

B. Spot markets, but no futures markets. We shall show that the only path which is consistent with short-run perfect foresight for all periods (or long-run perfect foresight) is the unique path converging to balanced growth. To see this most clearly, let us assume that there are markets at finite, predetermined, equally spaced intervals. ${ }^{7}$ (We need to replace the capital market differential equation by its discrete time analogue, but all the properties of the path remain unaffected.) Assume that the economy follows a path not converging to balanced growth. At some time $T-1$ for the rate of return on $K_{1}$ to equal that on $K_{2}$, there must be a sufficiently large capital loss on $K_{2}$ that $p_{2}{ }^{T-1}$ plus the change in price yields a negative value of $p_{2}{ }^{T}$. Consider the economy at $T-1$. Individuals, realizing that prices must be positive, know that the return on holding $K_{2}$ must exceed that on holding $K_{1}$; they all demand $K_{2}$, and its price "rises abruptly," 8 so that the realized price at $T-1$ is greater than the price that was expected at $T-2$ to prevail on the market at $T-1$. Thus, expectations are disappointed: the short-run perfect foresight assumption is violated.

Thus any initial price for which (2.5) and (2.6) lead eventually to a nonpositive price is inconsistent with the assumption that short-run perfect foresight holds in every period. But we have already shown that there is only one path for which prices are always positive: the prices which lead the economy to balanced growth. (The same argument holds, of course, for long-run perfect foresight.)

Thus paths which do not converge to balanced growth are inconsistent with the assumption that expectations are fulfilled at every instant of time. This has one very important implication: when capital is freely disposable, the problem of maximizing present

7. We present the argument in discrete time in order to avoid certain inessential problems arising when the set of dates before one of the prices goes to zero is an open set, i.e., when there exists no last moment.

8. In the continuous time model, $p_{2}$ would jump discontinuously at $T$. At $T$, short-run perfect foresight and instantaneously adjusted expectations differ, because at $T$ the left-hand time derivative of $p_{2}$ is not equal to the right-hand derivative. 
discounted value or maximizing intertemporal utility, given perfect foresight about prices, is well-defined only for the path which goes to balanced growth. Paths which do not converge to balanced growth may, however, be consistent with short-run perfect foresight for a finite number of periods. The question remains: is there anything to prevent the economy from setting off on an errant path?

First, consider an individual with long-run foresight, who foresees today that the nonnegativity constraint on the price of, say, $K_{2}$ will be binding at time $T$. He realizes that at time $T-1$ he - and everyone else - will demand $K_{2}$, so that its price will rise. But this means that if he had bought $K_{2}$ at $T-2$, he would have made a larger return on $K_{2}$ than on $K_{1}$. So he - and everyone else - will demand $K_{2}$ at $T-2$, which raises its price at $T-2$. And so on. Thus, the fact that the nonnegativity constraint is binding at $T$ will cause the price of $K_{2}$ to rise relative to that of $K_{1}$ today, and the only equilibrium prices in the market today will be those leading to balanced growth.

If individuals see only a finite time ahead, then, of course, the economy may set off on an errant path; but in finite time, individuals will foresee that the nonnegativity constraint is binding, expectations will not be fulfilled, and the economy will set off on another trajectory. Finally, if individuals see only one period ahead, then the economy may indeed pursue an errant path with expectations frustrated at time $T-1$ (if the nonnegativity constraint is binding at time $T$ ).

In this section, we investigated two alternative market structures corresponding to the model of Sections II and III. We showed that if there are Walrasian futures markets extending infinitely far into the future, then the economy will converge to balanced growth. We also showed that, in the case of spot markets with no futures markets, the only paths consistent with the short-run perfect foresight assumption holding in every period is the path converging to balanced growth. The following question remains: In the absence of long-run perfect foresight ${ }^{9}$ and futures markets, is there any mechanism which ensures that the economy does not set off initially on an errant path? To answer it, additional or alternative assumptions about market structures and behavior must be introduced. In Section V, we turn to these alternative assumptions.

9. It should be noted that previous writers have questioned the legitimacy of the perfect foresight assumption in economics. See, e.g., F. A. Hayek, "Economics and Knowledge," Essay II of Individualism and the Economic Order (University of Chicago Press, 1948), who argues that a statement like "perfect foresight ensures equilibrium" is essentially tautological. 


\section{Rationality and IrRationality}

Four market and behavioral assumptions are crucial to the model we have presented in Sections II and III: (1) Capital goods markets are perfect. (2) Investment is allocated in order to maximize short-run profits. (3) The savings decision is made according to some simple rule. (4) Individuals possess short-run perfect foresight (or at least instantaneously adjust their expectations). These four assumptions were made both because of their prominence in traditional economic theory and because they are thought to capture much of the spirit of how capitalist economies behave. In fact, however, alternative assumptions, involving more or less "rationality" and "perfection" may be made. We have investigated a large number of these, the most interesting of which are reported here.

A. Imperfect capital goods markets. For many kinds of machines, markets for renting and selling used capital goods are at best imperfect. Investors must then treat rentals differently from capital gains. To see how imperfect capital goods markets lend stability to the economy, consider the extreme case where there are no markets for renting or selling used capital goods, and hence no market prices or rental rates for used capital goods. An investor (now a producer) can buy either type of machine at a price of unity. And it is obvious that his investment decision will be to buy the machine that when cooperating with the investor's given stock of machines yields the higher marginal product. When $K_{1}$ and $K_{2}$ have the same marginal product, he will allocate his investment so as to maintain the equality of marginal products. Alternatively, even if there are rentals markets but there are two kinds of capitalists (or firms) one of which buys only $K_{1}$, and the other of which buys $K_{2}$, so that there is no trading of $K_{1}$ for $K_{2}$, and hence no capital market clearing equation, the system is also stable. ${ }^{1}$

$B$. Financial intermediation. In the preceding analysis, we have implicitly assumed, as we have throughout this paper, that there exist in the economy only real assets. We have, in particular, assumed that securities (shares of equity in firms) are absent from the economy. In reality, of course, securities markets are probably the best organized markets in the capitalist economy whereas used capital goods markets are notoriously imperfect. To the extent that perfect securities markets serve as a partial substitute for perfect capital goods markets our previous analysis captures some of the

1. This result holds whether capital goods are disposable or not. 
most important features of the process of capitalist development. ${ }^{2}$

There are, however, certain important aspects of actual financial markets that may play a stabilizing role in the capitalist economy. For example, holders of securities do not seem to be indifferent between expected income from capital gains and from dividends because it seems that often expectations about the former are held with less certainty than expectations about the latter. There are also all the "frictions" ("orderliness") imposed upon securities markets by the exchanges and the Securities and Exchange Commission. And, of course, institutions like the Federal Reserve System and the Treasury are designed to play a stabilizing role in the financial markets. To discuss these important issues in detail, however, would carry us beyond the scope of the present paper.

C. Static expectations. It should be clear from our previous discussion that capital gains is a primary source for destabilization in the economy. Nonexistent or imperfect capital markets "solve" the problem of instability by essentially eliminating the possibility of capital gains. There is an additional force ameliorating the instability arising from capital gains: Individuals are not likely to possess perfect foresight or, in the language of adaptive expectations, ${ }^{3}$ to adjust their expectations instantaneously. When, as along errant trajectories, price/earnings ratios become very small, individuals expect that the situation will not continue and bid the price up (and indeed, this expectation is justified, for we have already shown, price/earnings ratios cannot continue declining forever). In fact, Keynes argued in the General Theory that such conventional methods "of calculation will be compatible with a considerable measure of continuity and stability in our affairs, so long as we can rely on the maintenance of this convention." 4 In order to examine the implications of this for our model, assume that the price expected for next period is exactly equal to the price this period, $\eta_{i}^{t+\Delta t}=p_{i}^{t}$,

2. Our interpretation of the destabilizing role of financial markets seems to be consistent with Keynes's view of this matter. On p. 160 of the General Theory, Keynes considers the possibility of requiring the holding of real assets to be made "indissoluble, like marriage except by reason of death or other grave cause ... For this would force the investor to direct his mind to the long-term prospects and to those only." But Keynes rejects this scheme because by reducing the liquidity of physical assets, society would make the holding of money much more attractive; thus depressing real investment. But any instability in capital goods markets that is removed by this device may reappear in the market for securities.

3. Phillip Cagan in "The Monetary Dynamics of Hyperinflation," in Studies in the Quantity Theory of Money, ed. M. Friedman (University of Chicago Press, 1956), shows in a simple monetary economy with adaptive expectations, that the cruder the mechanisms of price adjustment the more likely is the system to be stable.

4. The General Theory, p. 152. 
$i=1,2$. Then the capital goods market clearing equation is simply $f_{1} / p_{1}=f_{2} / p_{2}$, so that the price of the capital good bearing the higher marginal product is always higher. Hence the economy always invests in the capital good with the higher marginal product (as we know, it should in order to get to balanced growth and for efficiency). Moreover, when $f_{1}=f_{2}, p_{1}=p_{2}$, and hence the economy first goes to the ray of equal marginal products and then proceeds along that ray to balanced growth.

\section{Concluding Comments}

The problems we have discussed in the context of allocation of investment in a dynamic economy belong to the more general theory of speculation and arise whenever holding more than one asset is a possibility, e.g., in international exchange speculation, in inventory policy, and in the demand for money. The common element is price appreciation. And the common problem is, as Samuelson has stated, ${ }^{\mathbf{5}}$ that "the market literally lives on its own dreams, and each individual at every moment of time is perfectly rational to be doing what he is doing."

The fact that imperfections and frictions are stabilizing influences should be reassuring to some advocates of the capitalist economy. However, to the classical economist, who argues for the competitive pricing system on the basis of its efficiency in allocating resources, ${ }^{6}$ it raises the problem of showing that a dynamic economy where trading can exist at any moment of time acts as if all transactions took place in an atemporal Walrasian market.

\section{Massachusetts Institute of Technology}

5. P. A. Samuelson, "Intertemporal Price Equilibrium: A Prologue to the Theory of Speculation," Weltwirtschaftliches Archiv, Band 79, Heft 2 (Hamburg: Hoffmann \& Campe Verlag, Dec. 1957), p. 215. Samuelson observes that "history tells us that all tulip manias have ended in finite time. Every 'Ponzi scheme' and every chain letter scheme finally runs out. Every bubble is some day pricked." We have shown, in the context of our model, some reasons why speculative booms must end in finite time. Op. cit., pp. $215-16$.

6. Contrast our approach with the attempts of Samuelson and Kurz to solve the "Hahn problem." See P. A. Samuelson, "Indeterminacy of Development in a Heterogeneous-Capital Model with Constant Saving Propensity," in $\mathrm{K}$. Shell (ed.), Essays on the Theory of Optimal Economic Growth (Cambridge, Mass.: M.I.T. Press, 1967), pp. 219-31, and M. Kurz, "The General Instability of a Class of Competitive Growth Processes," Technical Report No. 147 (Dec. 16, 1966), Institute for Mathematical Studies in the Social Sciences, Stanford, California. Both Samuelson and Kurz show how instability arises in related planning models and how for the planned economy the transversality conditions ensure long-run balanced growth. Our approach, however, is to ask: What forces for stability and efficiency exist in the capitalist system? 